Yüzüncü Yil Üniversitesi
Tarim Bilimleri Dergisi

Araştırma Makalesi (Research Article)

\title{
Depolama Süresinin Farklı Kurutma Yöntemleri ile Kurutulmuş Kamkat Dilimlerinin Bazı Kalite Özelliklerine Etkisi**
}

\author{
Demet YILDIZ TURGUT ${ }^{* 1}$, Ayhan TOPUZ ${ }^{2}$ \\ ${ }^{1}$ Batı Akdeniz Tarımsal Araştırma Enstitüsü Müdürlüğü, 07100, Antalya, Türkiye \\ ${ }^{2}$ Akdeniz Üniversitesi, Mühendislik Fakültesi, Gida Mühendisliği Bölümü, 07070, Antalya, Türkiye \\ ${ }^{1}$ https://orcid.org/0000-0002-7486-3701 ${ }^{2}$ https://orcid.org/0000-0002-6610-9143 \\ *Sorumlu yazar e-posta: demet.yildizturgut@tarimorman.gov.tr
}

\section{Makale Bilgileri \\ Geliş: 06.11.2019 \\ Kabul: 18.01.2020 \\ Online Yayınlanma 31.03.2020 \\ DOI: $10.29133 /$ yyutbd.643636}

\section{Anahtar kelimeler}

Askorbik asit,

Depolama,

5-hidroksimetilfurfural,

Kurutma,

Su aktivitesi.
Öz: Bu çalışmada farklı kurutma yöntemleri ile kurutulmuş kamkat dilimleri oda sıcaklığında 4 ay depolanmış ve depolama süresinde ürün kalitesi ve stabilitesi incelenmiştir. Bu amaçla, kamkat dilimleri suda haşlama ön işlemi ve ön işlemsiz olarak sıcak hava, vakum, ultrason destekli ozmotik ön kurutma sonrası sıcak hava ve mikrodalga destekli sıcak hava kurutma olmak üzere 4 kurutma yöntemi ile kurutulmuştur. Depolama süresinde kurutulmuş kamkat dilimlerinin nem içerikleri ve su aktivitesi değerleri artış göstermiş, en düşük artış ön işlemsiz sıcak hava kurutma yöntemi ile kurutulan örneklerde belirlenmiştir. Genel olarak, depolamanın sonunda kurutulmuş kamkat dilimlerinin $\mathrm{L}^{*}, \mathrm{~b}^{*}$, kroma, hue açısı değerleri azalış göstermiş, a ve TRD değerleri ise artış göstermiştir. Depolama sürecinde, HMF değerleri $0.39-46.79 \mathrm{mg} / \mathrm{kg}$ arasında değişim göstermiştir. Depolama periyodunda kurutulmuş örneklerin askorbik asit içeriğinin \%28.3675.61 oranında kayba uğradığı gözlenmiştir. Çalışma sonucunda kamkat dilimlerinin ön işlemsiz olarak kurutulmasının 4 aylık depolama süresinde incelenen kalite özellikleri açısından daha uygun olduğu belirlenmiştir.

\section{Effect of Storage Time on Some Quality Characteristics of Dried Kumquat Slices by Different Drying Methods}

\section{Article Info}

Received: 06.11.2019

Accepted: 18.01.2020

Online Published 31.03.2020

DOI: 10.29133/yyutbd.643636

\section{Keywords}

Ascorbic acid,

Storage,

5-hydroxymethylfurfural,

Drying,

Water activity.

\begin{abstract}
In this study, dried kumquat slices by different drying methods were stored at room conditions for 4 months and the product quality and stability were investigated during storage. For this purpose, the kumquat slices were dried by four drying methods including hot air, vacuum, ultrasound assisted osmotic predrying with hot air, and microwave assisted hot air drying with pretreatment by water blanching and without pretreatment. The moisture content and water activity values of dried kumquat slices increased during storage, and the lowest increase was determined in samples dried by hot air drying method without pretreatment. In general, $\mathrm{L}^{*}, \mathrm{~b}^{*}$, chroma, hue angle values decreased, while $\mathrm{a}^{*}$ and TRD values increased in all dried samples at the end of the storage. HMF values were ranged from 0.39 to $46.79 \mathrm{mg} / \mathrm{kg}$ during storage. It was observed that the ascorbic acid content of dried samples lost 28.36-75.61\% during storage period. As a result of the study, it has been determined that drying of kumquat slices by without pretreatment is more suitable in terms of the examined quality properties during storage for 4 months.
\end{abstract}

\footnotetext{
*** Bu çalışma "Farklı Yöntemlerle Kurutulmuş Kamkatın (Fortunella margarita Swing.) Bazı Kalite Özellikleri ve Depolamaya Bağlı Değişimi” adlı doktora tezinin bir bölümüdür.
} 


\section{Giriş}

Meyve ve sebzelerin içerdiği \%80-95 oranındaki su bu ürünlerin kısa sürede bozulmalarına neden olabilmektedir. Kurutma işlemi ile gıdaların bileşiminde bulunan, serbest su içeriği azaltılmakta, dolayısıyla gıdaların su aktiviteleri düşürülmekte ve böylece depolama sırasında meydana gelebilecek mikrobiyolojik, kimyasal ve enzimatik bozulmaların engellenmesi mümkün olabilmektedir (Cemeroğlu ve ark., 2003; Us, 2006; Rodriguez ve ark., 2017). Kurutma ile gida maddelerinin raf ömrünün uzatılması yanında, paketleme, taşıma ve depolama maliyetlerinin düşürülmesi sağlanmaktadır. Meyve ve sebzelerdeki hasat sonrası kayıplar kurutma işlemi ile \%70 oranında azaltılabilmektedir (Cemeroğlu ve ark., 2003; Doymaz, 2007; Saçılık, 2007; Darvishi ve ark., 2014).

Kurutma işlemi sırasında 1sı ve kütle aktarımı sebebiyle son ürünün renk, yapı, aroma ve besin değeri gibi kalite özelliklerini etkileyen birçok fiziksel, kimyasal ve biyokimyasal değişiklikler meydana gelmektedir (Di Scala ve Crapiste, 2008; Vega-Galvez ve ark., 2009). Yüksek ve standart kalitede kurutulmuş ürün elde etmeye yönelik olarak birçok endüstriyel kurutma metodu geliştirilmiştir. Bunlar arasında mikrodalga kurutma, vakum kurutma, sıcak hava kurutma, ozmotik dehidrasyon ve dondurarak kurutma en yaygın kullanılan kurutma yöntemleridir (Krokida ve Maroulis, 2000; Marques ve ark., 2006; Sagar ve Kumar, 2010).

Son yıllarda sağ liklı olmaları ve kullanım kolaylıkları nedeniyle kurutulmuş atıştırmalık meyve ürünlerine olan talep giderek artmaktadır (Joshi ve ark., 2011; Jiang ve ark., 2017). Günümüzde gıdaların gerek işlenmesi gerekse depolanması aşamalarında sadece mikrobiyolojik ve kimyasal bozulmaların engellenmesi değil aynı zamanda yararlı bileşenlerin yüksek derecede korunması gıda endüstrisinin en önemli amaçlarındandır (Methakhup ve ark., 2005; Udomkun ve ark., 2016). Kurutulmuş meyveler depolama ve taşıma sırasında 1şık, oksijen, sıcaklık ve nem gibi birçok çevresel etkenlere maruz kalabilmektedir. Bu faktörlerin etkisiyle kurutulmuş ürünlerde esmerleşme ve kimyasal bozulma reaksiyonları sonucu renk, tat, aroma ve besin içeriğinde kayıplar olabilmektedir (Udomkun ve ark., 2016). Kurutulmuş ürünlerin depolanması sırasındaki kalite değişimleri materyalin fiziksel ve kimyasal özellikleri, kurutma yöntemleri, kurutma öncesi uygulanan ön işlemler, ambalaj materyali, depolama sıcaklığı, nemi ve süresi ile çevresel faktörlere bağlıdır (Uddin ve ark., 2002; Yen ve ark., 2008; Topuz ve ark., 2009; Gölükcü, 2015; Udomkun ve ark., 2016).

Rutacea familyasının Fortunella cinsi içerisinde yer alan kamkat, ülkemizde Doğu Karadeniz, Ege ve Akdeniz Bölgesi'nde yetiştirilen bir bitki türüdür. Kamkat meyvesi hasattan sonra hem içerdiği \%80'in üzerindeki su miktarı hem de yüksek solunum hızı nedeniyle çabuk bozulabilen bir meyvedir ve soğukta muhafaza ömrü ancak birkaç haftadır (Schirra ve ark., 2008). Bu meyve diğer turunçgil meyvelerine benzemekle birlikte, taze tüketim açısından kabuğu ile birlikte tüketilebilmektedir (Koyasaka ve Bernhard, 1983). Kamkat meyvesi endüstride reçel, marmelat, şarap, likör gibi ürünlerin dışında, özellikle yetiştiriciliğinin yaygın yapıldığı Uzak Doğu ülkelerinde kurutularak değerlendirilmektedir (Chiu ve Chang, 1998; Wang et al., 2012; Lou ve ark., 2015). Literatürde kamkatın kurutulması ile ilgili sınırlı sayıda araştırmaya rastlanmıştır (Lou ve ark., 2015; İzli ve ark., 2018; Özcan-Sinir ve ark., 2018).

$\mathrm{Bu}$ çalışmada ön işlemli (haşlama) ve ön işlemsiz olarak farklı yöntemlerle kurutulmuş kamkat dilimlerinin, 4 aylık depolama süresinde su aktivitesi ve renk özellikleri ile askorbik asit ve 5hidroksimetilfurfural içeriğindeki değişimlerin incelenmesi amaçlanmıştır.

\section{Materyal ve Yöntem}

Çalışmada kullanılan "Nagami” (Fortunella margarita Swingle) kamkat çeşidine ait meyveler Antalya Batı Akdeniz Tarımsal Araştırma Enstitüsü (BATEM) parsellerinden 2017 Ocak ayı içerisinde hasat edilmiştir. Kurutma çalışmaları öncesi, hasat edilen meyvelerin bazı fiziksel ve kimyasal özellikleri belirlenmiştir.

\subsection{Kurutma öncesi uygulanan ön işlemler}

Kurutma çalışmaları öncesinde meyveler musluk suyu ile yıkanıp kurulanmış ve kalınlığı ayarlanabilen paslanmaz çelik bıçaklı dilimleyici (OXO Good Grips, New York, ABD) yardımıyla silindirik olarak $4 \mathrm{~mm}$ kalınlığında dilimlenmiştir. Kamkat dilimleri ön işlemli (haşlama) ve ön işlemsiz 
olarak iki gruba ayrılmıştır. Ön işlem olarak kamkat dilimleri $5 \mathrm{dk}$ süre ile $100^{\circ} \mathrm{C}$ 'deki saf su içerisinde meyve su oranı 2:5 olacak şekilde haşlama işlemine tabi tutulmuştur. Daha sonra süzülerek, filtre kâğıdı üzerinde suları giderilmiştir.

\subsection{Kurutma yöntemleri ve depolama}

Kamkat dilimleri ön işlemli ve ön işlemsiz olarak sıcak hava (SH), vakum (V), ultrason destekli ozmotik ön kurutma sonrası sıcak hava ile tamamlayıcı kurutma (US-SH) ve mikrodalga destekli sicak hava kurutma (M-SH) olmak üzere 4 farklı kurutma yöntemiyle yaş baza göre \% $12 \pm 1$ nem içeriğine kadar kurutulmuştur. Kurutma işlemlerinde her uygulama için $400 \mathrm{~g}$ kamkat dilimi kullanılmıştır. Kurutma uygulamaları 3 tekrarlı olarak gerçekleştirilmiştir. Kurutma çalışmalarına ait diyagram Şekil 1 'de verilmiștir.

Kamkat dilimlerinin sicak hava ile kurutulmasinda Laboratuvar tipi tepsili kurutucu (EKSİS Endüstriyel Kurutma Sistemleri, Isparta) kullanılmıştır. Kurutma denemeleri $60^{\circ} \mathrm{C}$ hava sıcaklığında ve $1.3 \mathrm{~m} / \mathrm{s}$ sabit hava hızında gerçekleştirilmiştir. Vakum kurutma denemeleri vakumlu kurutucuda (Vacucell VUS-B2V/VU55, MMM Medcenter, Almanya) $60^{\circ} \mathrm{C}$ sicaklikta ve $15 \mathrm{kPa}$ vakum altında gerçekleştirilmiştir. Ultrason destekli ozmotik kurutma işleminde, ön işlemli ve ön işlemsiz kamkat dilimleri $35 \mathrm{kHz}$ frekansta çalışan ultrasonik su banyosunda (Bandelin, Model RK-510 H, Almanya) $\% 55$ şeker çözeltisi içerisinde meyve çözelti oranı $1: 5$ olacak şekilde $30^{\circ} \mathrm{C}$ 'de 2 saat ön kurutmaya tabi tutulmuştur. İşlem sonrasında çözeltiden çıkarılan dilimlerin yüzeyindeki çözelti kalıntısını uzaklaştırmak amacıyla saf suya daldırılmış ve filtre kâğıdı ile kurulanmıştır. Ultrason destekli ozmotik kurutma sonrası sıcak hava kurutma firınında $60^{\circ} \mathrm{C}$ hava sicaklığında ve $1.3 \mathrm{~m} / \mathrm{s}$ sabit hava hızında tamamlayıcı kurutma yapılmıştır. Mikrodalga destekli sıcak hava kurutma işlemi çok fonksiyonlu mikrodalga fırında (Siemens HB86K575) 90 Watt (W) güçte (spesifik mikrodalga gücü $4.44 \mathrm{~W} / \mathrm{g}$ ), $60^{\circ} \mathrm{C}$ hava sıcaklığında ve $1.3 \mathrm{~m} / \mathrm{s}$ sabit hava hızında gerçekleştirilmiştir.

Kurutma çalışmaları ön işlemsiz kamkat dilimlerinde SH, V, US-SH ve M-SH yöntemleri için sırasıyla 200, 810, 300 ve 75 dk, ön işlemli kamkat dilimlerinde ise sırasıyla 90, 600, 240 ve $65 \mathrm{dk}$ sürdürülmüş̧ür.

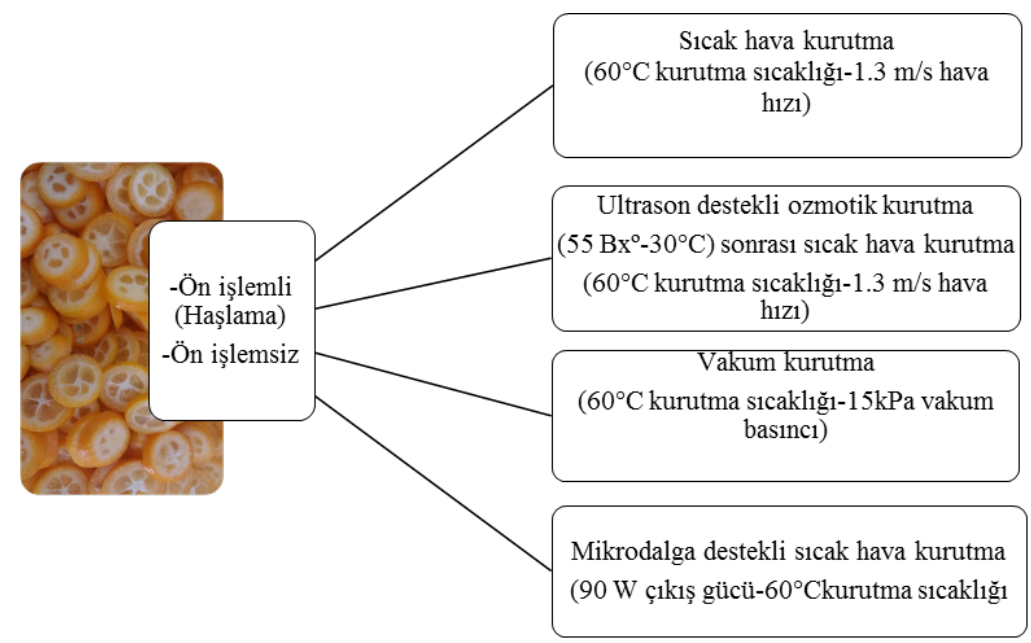

Şekil 1. Kamkat dilimlerinin kurutma uygulamalarına ait diyagram.

Kurutulmuş kamkat dilimleri ticari koşullarda olduğu gibi 100 g'l1k düşük yoğunluklu polietilen torbalar içerisinde ve oda sicaklığında $\left(22-24^{\circ} \mathrm{C}\right) 4$ ay süreyle depolanmıştır. Depolama süresince her ay ürünlerin nem miktarı, su aktivitesi $\left(\mathrm{a}_{\mathrm{w}}\right)$, renk değerleri $\left(\mathrm{L}^{*}, \mathrm{a}^{*}, \mathrm{~b}^{*}\right.$, kroma, hue açısı, toplam renk değişimi), HMF (5-hidroksimetilfurfural) ve askorbik asit içerikleri belirlenerek, bu kriterlerin değişimi incelenmiştir. 


\subsection{Analizler}

Kamkat meyvelerinde meyve ağırlığı (g) hassas terazi yardımıyla, meyve çapı (mm) ve boyu $(\mathrm{mm})$ ise dijital bir kumpas ile belirlenmiştir. Meyvelerin $\mathrm{pH}$ ve titrasyon asitliği (susuz sitrik asit cinsinden) değerleri ile suda çözünebilir kuru madde miktarı (SÇKM) ise Cemeroğlu (2007) tarafından önerilen yöntemlerle saptanmıştır. Örneklerin nem içerikleri AOAC (2000) (Metot 986.21) nem tayin yöntemine göre belirlenmiştir. Örneklerin su aktivitesi değerleri su aktivitesi ölçüm cihazı (Novasina Lab-swift, İsviçre) ile $25^{\circ} \mathrm{C}$ 'de belirlenmiştir. Kurutulmuş kamkat dilimlerinin CIE (Uluslararası Aydınlatma Sistemi-Commission Internationale de l'Eclairage) L*, a* , b renk değerleri Minolta CR 400 (Osaka, Japonya) renk ölçüm cihazı ile üç farklı noktadan D65 1şık kaynağı kullanılarak belirlenmiştir. Ölçülen L*, a*, b* değerlerinden kroma (renk doygunluğu) 1 No'lu, hue açısı (renk yoğunluğu açısı) 2 No'lu, TRD (toplam renk değişimi) 3 No'lu eşitlikler yardımıyla hesaplanmıştır (Chen et al., 2005; Pathare et al., 2013; Darvishi et al., 2014; Akdaş and Başlar, 2014; Ghanem Romdhane et al., 2015).

$$
\begin{gathered}
C=\sqrt{a^{* 2}+b^{* 2}} \\
H^{\circ}=\tan ^{-1} \frac{b^{*}}{a^{*}} * \frac{180}{\pi} \\
T R D=\sqrt{\left(\Delta L^{*}\right)^{2}+\left(\Delta a^{*}\right)^{2}+\left(\Delta b^{*}\right)^{2}}
\end{gathered}
$$

Askorbik asit analizi Sdiri ve ark. (2012)' ye göre yüksek perfonsmanslı sıvı kromatografisi (HPLC) cihazı ile gerçekleştirilmiştir. Bu amaçla örnekler \%3'lük metafosforik asit $\left(\mathrm{HPO}_{3}\right)$ çözeltisi ile ekstrakte edilmiştir. Elde edilen ekstraktlar santrifüj sonrası, $0.45 \mu \mathrm{m}$ gözenek çaplı membran filtreden (Cronus, SMI-Labhut Ltd, Gloucester, Birleşik Krallık) geçirilerek HPLC cihazına verilmiştir. Analizde Shimadzu 2030 C 3 d Prominence-i (Japonya) model HPLC cihazı ile aynı model PDA (Photo-diode Array) dedektör kullanılmıştır. Analizde mobil faz olarak pH'sı ortofosforik asit $\left(\mathrm{H}_{3} \mathrm{PO}_{4}\right)$ çözeltisi ile pH'sı 2.3'e ayarlanmış \%2'lik potasyum dihidrojen fosfat $\left(\mathrm{KH}_{2} \mathrm{PO}_{4}\right)$ kullanılmıştır. Analiz İnertsil ODS3 C-18 kolon (5 $\mu \mathrm{m}, 250 \times 4.6$ i.d.) (GL Sciences, Japonya) ile $243 \mathrm{~nm}$ dalga boyunda, izokratik olarak $0.5 \mathrm{~mL} / \mathrm{dk}$ akış hızında gerçekleştirilmiştir. Kullanılan enjeksiyon hacmi $10 \mu \mathrm{L}$, kolon sıcaklığ 1 ise $25^{\circ} \mathrm{C}$ 'dir. Sonuçlar 1-200 $\mathrm{mg} / \mathrm{L}$ konsantrasyon aralığında hazırlanan standart askorbik asit eğrisi ve bu eğriyi tanımlayan eşitliğe göre $\mathrm{mg} / 100 \mathrm{~g} \mathrm{~km}$ (kuru madde) olarak hesaplanmıştır.

Örneklerin HMF içeriği HPLC cihazı ile Tontul and Topuz (2017) tarafından önerilen yönteme göre belirlenmiştir $\mathrm{Bu}$ doğrultuda kurutulmuş örnekler saf su ile 10 kat seyreltilmiş, $0.45 \mu \mathrm{m}$ gözenek çaplı membran filtreden (Cronus, SMI-Labhut Ltd, Gloucester, Birleşik Krallık) geçirilerek HPLC cihazına verilmiştir. Sonuçlar $0.5-20 \mathrm{mg} / \mathrm{L}$ konsantrasyon aralığında hazırlanan standart HMF eğrisi ve bu eğriyi tanımlayan eşitliğe göre mg/100 g km olarak hesaplanmıştır. Analiz Shimadzu 20 AD serisi (Shimadzu, Tokyo, Japonya) HPLC cihazında, SPD-M20A model PDA dedektör ile gerçekleştirilmiştir.

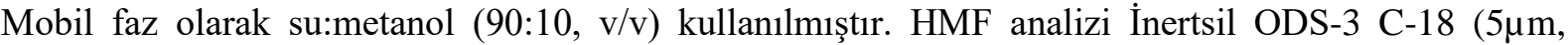
250x4.6 i.d.) (GL Sciences, Japonya) kolon ile $285 \mathrm{~nm}$ dalga boyunda, $1 \mathrm{~mL} / \mathrm{dk}$ akış hızında izokratik olarak gerçekleştirilmiştir. Analizde kullanılan enjeksiyon hacmi $20 \mu \mathrm{L}$, kolon sıcaklığ 1 ise $25^{\circ} \mathrm{C}$ 'dir.

Çalışma 3 tekrarlı yürütülmüştür. Analiz sonuçlarına varyans analizi uygulanmış, önemli bulunan farklılıklar Duncan çoklu karşılaştırma testine tabi tutulmuştur. İstatistiksel analizlerde SAS istatistik paket programı (Version 6.12, SAS Institute, Cary, NC, ABD) kullanılmış, sonuçlar ortalama \pm standart sapma (ort \pm std) olarak verilmiştir.

\section{Bulgular}

\subsection{Materyal olarak kullanılan kamkat meyvesinin bazı özellikleri}

Araştırma kapsamında kullanılan Nagami çeşidi kamkatın incelenen bazı fiziksel ve kimyasal özellikleri Çizelge 1'de yer almaktadır. 
Çizelge 1. Araştırmada kullanılan kamkat meyvelerinin bazı fiziksel ve kimyasal özellikleri

\begin{tabular}{|c|c|}
\hline Özellik & Değer (ort \pm std) \\
\hline Meyve ağırlığı (g) & $12.58 \pm 1.60$ \\
\hline Meyve çap 1 (mm) & $2.24 \pm 0.11$ \\
\hline Meyve boyu (mm) & $3.52 \pm 0.26$ \\
\hline $\mathrm{pH}$ & $3.21 \pm 0.20$ \\
\hline Titrasyon asitliği $(\mathrm{g} / 100 \mathrm{~g})$ & $1.84 \pm 0.32$ \\
\hline SÇKM $\left({ }^{\circ} \mathrm{Bx}\right)$ & $15.11 \pm 1.21$ \\
\hline Su aktivitesi & $0.903 \pm 0.03$ \\
\hline Toplam kuru madde (\%) & $15.25 \pm 3.06$ \\
\hline Askorbik asit (mg/100 g km) & $298.35 \pm 0.76$ \\
\hline \multicolumn{2}{|c|}{ Meyve kabuğunun renk değerleri } \\
\hline $\mathrm{L}^{*}$ & $61.26 \pm 1.52$ \\
\hline$a^{*}$ & $28.60 \pm 2.21$ \\
\hline $\mathrm{b}^{*}$ & $59.95 \pm 2.44$ \\
\hline Kroma & $66.46 \pm 2.49$ \\
\hline Hue açısı & $64.49 \pm 1.85$ \\
\hline \multicolumn{2}{|l|}{ Meyve püresinin renk değerleri } \\
\hline $\mathrm{L}^{*} \mathrm{p}(\mathrm{c})$ & $62.14 \pm 0.16$ \\
\hline$a^{*}$ & $3.70 \pm 0.32$ \\
\hline $\mathrm{b}^{*}$ & $53.99 \pm 0.58$ \\
\hline Kroma & $54.12 \pm 0.77$ \\
\hline Hue açıs1 & $86.07 \pm 0.66$ \\
\hline
\end{tabular}

\subsection{Nem içeriği ve su aktivitesindeki değişimler}

Depolama sürecinde ön işlemin, kurutma yöntemlerinin ve depolama süresinin örneklerin nem içeriğine etkisi önemli $(p<0.05 ; p<0.001)$ bulunurken, ön işlem $\mathrm{x}$ kurutma yöntemi $\mathrm{x}$ depolama süresi interaksiyonunun etkisi önemsiz bulunmuştur (Çizelge 2). Depolamanın başlangıcında örneklerin nem içerikleri (\%11.65-12.90) arasında önemli bir fark bulunmazken ( $p>0.05)$, depolama süresinin sonunda en yüksek nem içeriği ön işlemli olarak M-SH yöntemi ile kurutulan örneklerde (\%15.12), en düşük nem içeriği ise ön işlemsiz SH örneğinde belirlenmiştir (Çizelge 3). Depolama süresi içerisinde örneklerin nem içeriği \% 11.08-25.40 oranında artış göstermiştir. En az artış ön işlemsiz SH yöntemi ile kurutulan örneklerde gözlenirken, bu artış önemsiz bulunmuştur $(p>0.05)$. Depolamanın sonunda nem içeriğinde en yüksek artış ise ön işlemli US-SH yöntemi ile kurutulan örneklerde belirlenmiştir. Genel olarak ön işlemli kurutulan örneklerdeki nem artış oranı (\%14.01-25.40), ön işlemsiz kurutulanlardan (\%11.08-20.29) daha fazla olmuştur.

Kurutulmuş kamkat dilimlerinin depolama süresine bağlı olarak $a_{w}$ değişimi Çizelge 3 'te verilmiştir. Tüm varyasyon kaynaklarının depolama süresince $\mathrm{a}_{\mathrm{w}}$ değerleri üzerine etkisi önemli $(p<0.001)$ bulunmuştur (Çizelge 2). Depolamanın başlangıcında en yüksek su aktivitesi değerleri ön işlemsiz US-SH, M-SH ve ön işlemli V yöntemi ile kurutulan örneklerde, en düşük su aktivitesi ise ön işlemsiz SH yöntemi ile kurutulan örneklerde belirlenmiştir $(p<0.05)$. Depolama süresi içerisinde ise en yüksek $\mathrm{a}_{\mathrm{w}}$ değerleri ön işlemli M-SH yöntemi ile kurutulan örneklerde belirlenmiştir. Depolama sonucu en yüksek nem içeriğine sahip örneğin ön işlemli M-SH yöntemi ile kurutulan örnek olduğu görülmektedir (Çizelge 4). Depolamanın sonunda tüm örneklerin $\mathrm{a}_{\mathrm{w}}$ değerleri \%34.38-82.22 oranında artış göstermiştir. En yüksek artış oranı ön işlemli SH, en düşük artış oranı ise ön işlemsiz SH yöntemi ile kurutulan örneklerde gerçekleşmiştir. Depolama sonunda nem içeriğindeki değişime benzer şekilde, ön işlemli kurutulan örneklerdeki $\mathrm{a}_{\mathrm{w}}$ artış oran1 (\%64.85-82.22), ön işlemsiz kurutulan örneklerden (\%34.38-61.67) daha yüksek olmuştur. 
Çizelge 2. Depolama sürecinde incelenen kalite özelliklerine ait varyans analiz tablosu

\begin{tabular}{|c|c|c|c|c|c|c|c|c|c|c|c|}
\hline $\begin{array}{l}\text { Varyasyon } \\
\text { kaynakları }\end{array}$ & SD & $\begin{array}{l}\text { Nem } \\
\text { içeriği }\end{array}$ & $\overline{a_{w}}$ & $\mathrm{~L}^{*}$ & $\mathrm{a}^{*}$ & $\mathrm{~b}^{*}$ & Kroma & $\begin{array}{l}\text { Hue } \\
\text { açis1 }\end{array}$ & TRD & HMF & $\begin{array}{c}\text { Askorbik } \\
\text { asit }\end{array}$ \\
\hline Ön islem (Ö) & 1 & & ${ }^{* * * *}$ & ${ }^{* * * *}$ & ${ }^{* * * *}$ & *** & ${ }^{* * * *}$ & & **** & **** & **** \\
\hline $\begin{array}{l}\text { Kurutma yöntemi } \\
\text { (K) }\end{array}$ & 3 & **** & $* * *$ & $* * *$ & $* * *$ & $* * *$ & ** & $* * *$ & $* * *$ & $* * *$ & $* * *$ \\
\hline $\begin{array}{l}\text { Depolama süresi } \\
\text { (D) }\end{array}$ & 4 & *** & $* * *$ & $* * *$ & $* * *$ & $* * *$ & $* * *$ & ${ }^{* * * *}$ & *** & $* * *$ & $* * *$ \\
\hline $\begin{array}{c}\text { Ö x K x D } \\
\text { Hata }\end{array}$ & $\begin{array}{l}12 \\
80\end{array}$ & - & *** & *** & $* *$ & * & ** & - & - & **** & **** \\
\hline
\end{tabular}

Çizelge 3. Farklı yöntemlerle ön işlemli ve ön işlemsiz kurutulmuş kamkat dilimlerinin depolama sürecinde nem içeriklerinin ve su aktivitesi değerlerinin değişimi.

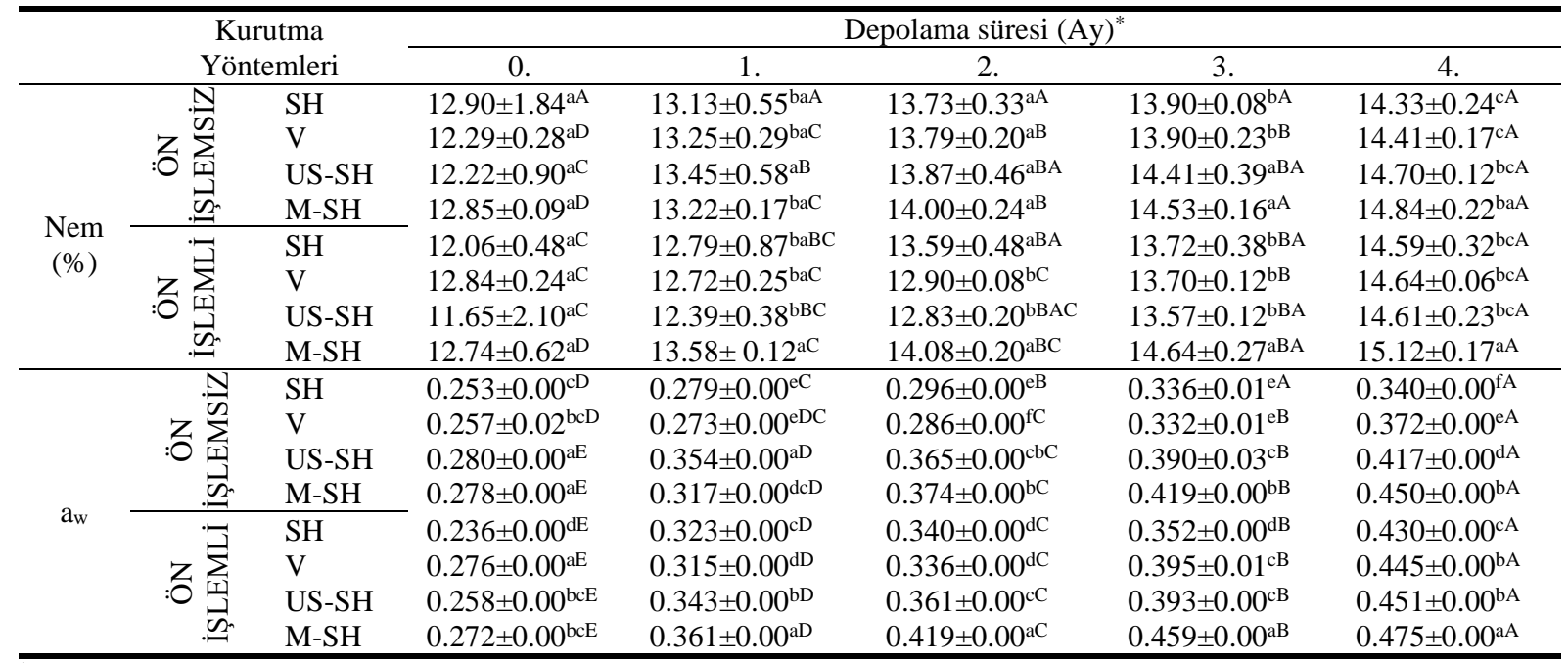

*Aynı sütundaki farklı üstel küçük harflerle aynı satırdaki farklı üstel büyük harfler ortalamaların $p<0.05$ seviyesinde farklı olduğunu gösterir $(\mathrm{n}=3)$.

\subsection{Renk değerlerindeki değişimler}

Kurutulmuş kamkat dilimlerinin depolamaya bağlı renk değerleri değişimi Çizelge 4'te yer almaktadır. Varyans analizi sonuçlarına (Çizelge 2) göre varyasyon kaynaklarının kurutulmuş kamkat dilimlerinin depolama süresi boyunca $\mathrm{L}^{*}$ değerlerine etkisi $p<0.001$ düzeyinde önemli bulunmuştur. Depolama başlangıcında ve sonunda en yüksek L $^{*}$ değeri ön işlemli US-SH yöntemi ile kurutulan örneklerde belirlenmiştir. Depolama süresi boyunca $L^{*}$ değerleri bazı uygulamalarda dalgalanmalar gösterse de genel olarak başlangıca göre \%6.46 ile \%29.88 oranında azalış göstermiştir (Çizelge 4). En düşük oranda azalış ön işlemli US-SH yönteminde, en yüksek oranda azalış ise ön işlemsiz V yönteminde gerçekleşmiştir.

Depolama süresince varyasyon kaynaklarının kurutulmuş kamkat dilimlerinin a* değerlerine etkisi önemli $(p<0.001 ; p<0.01)$ bulunmuştur (Çizelge 2$)$. Depolama sonunda ön işlemli ve ön işlemsiz M-SH yöntemi ile kurutulan örnekler hariç, diğer örneklerin $a^{*}$ değerleri \%5.40-78.33 arasında artış göstermiştir. $a^{*}$ değerindeki en düşük artış oranı ön işlemli $V$, en yüksek artış oranı ise ön işlemsiz USSH yöntemiyle kurutulan örneklerde gerçekleşmiştir. a* değerindeki artış kırmızılığın artışına yani esmerleşme reaksiyonlarına işaret etmektedir (Krokida ve Maroulis 2000). Depolama sonunda en yüksek a* değeri ön işlemsiz SH örneğinde, en düşük a* değeri ise ön işlemli US-SH yönteminde tespit edilmiştir. 
Çizelge 4. Farklı yöntemlerle ön işlemli ve ön işlemsiz kurutulmuş kamkat dilimlerinin depolama sürecinde renk değerleri değişimi.

\begin{tabular}{|c|c|c|c|c|c|c|c|}
\hline \multirow{2}{*}{$\begin{array}{l}\text { Renk } \\
\text { parametreleri }\end{array}$} & \multirow{2}{*}{\multicolumn{2}{|c|}{$\begin{array}{l}\text { Kurutma } \\
\text { Yöntemleri }\end{array}$}} & \multicolumn{5}{|c|}{ Depolama süresi (Ay) } \\
\hline & & & 0. & 1. & 2. & 3. & 4. \\
\hline \multirow{8}{*}{$\mathrm{L}^{*}$} & & $\mathrm{SH}$ & $69.16 \pm 0.97^{\mathrm{bC}}$ & $72.91 \pm 1.11^{\mathrm{aA}}$ & $70.95 \pm 0.87^{\mathrm{aB}}$ & $65.78 \pm 0.62^{\mathrm{bD}}$ & $53.39 \pm 0.89^{\mathrm{dcE}}$ \\
\hline & $\sum^{\pi}$ & $\mathrm{V}$ & $70.29 \pm 0.33^{\mathrm{bA}}$ & $67.17 \pm 1.21^{\mathrm{cB}}$ & $66.80 \pm 0.46^{\mathrm{bB}}$ & $60.44 \pm 2.24^{\mathrm{dcC}}$ & $51.39 \pm 0.78^{\mathrm{dD}}$ \\
\hline & & US-SH & $69.09 \pm 1.48^{\mathrm{bA}}$ & $68.27 \pm 1.23^{\mathrm{cbA}}$ & $67.75 \pm 1.42^{\text {baA }}$ & $66.62 \pm 0.95^{\mathrm{bA}}$ & $61.18 \pm 2.48^{\mathrm{bB}}$ \\
\hline & & $\mathrm{M}-\mathrm{SH}$ & $66.12 \pm 0.56^{\mathrm{cA}}$ & $66.69 \pm 1.01^{\mathrm{cA}}$ & $61.71 \pm 0.71^{\mathrm{cB}}$ & $61.45 \pm 1.19^{\mathrm{cB}}$ & $54.51 \pm 0.62^{\mathrm{cC}}$ \\
\hline & & $\mathrm{SH}$ & $57.39 \pm 0.63^{\mathrm{eB}}$ & $58.62 \pm 0.23^{\mathrm{eB}}$ & $61.39 \pm 2.87^{\mathrm{cA}}$ & $58.46 \pm 1.62^{\mathrm{dB}}$ & $52.34 \pm 0.18^{\mathrm{dcC}}$ \\
\hline & $\xi$ & $\mathrm{V}$ & $61.66 \pm 1.19^{\mathrm{dA}}$ & $61.22 \pm 0.44^{\mathrm{dA}}$ & $57.85 \pm 1.67^{\mathrm{dB}}$ & $54.77 \pm 0.28^{\mathrm{eC}}$ & $53.49 \pm 2.03^{\mathrm{dcC}}$ \\
\hline & & US-SH & $71.35 \pm 0.22^{\mathrm{aA}}$ & $69.77 \pm 1.58^{\mathrm{bBA}}$ & $69.87 \pm 3.86^{\mathrm{baBA}}$ & $72.52 \pm 1.59^{\mathrm{aA}}$ & $66.74 \pm 0.48^{\mathrm{aB}}$ \\
\hline & & M-SH & $60.75 \pm 0.15^{\mathrm{dA}}$ & $59.02 \pm 0.13^{\mathrm{eB}}$ & $56.10 \pm 0.89^{\mathrm{dC}}$ & $52.14 \pm 0.33^{\mathrm{fE}}$ & $53.78 \pm 1.65^{\mathrm{dcD}}$ \\
\hline \multirow{8}{*}{$a^{*}$} & $\vec{N}$ & SH & $7.09 \pm 0.07^{\mathrm{eB}}$ & $5.01 \pm 0.80^{\mathrm{fC}}$ & $5.64 \pm 0.29^{\mathrm{cC}}$ & $6.41 \pm 0.07^{\mathrm{dB}}$ & $8.78 \pm 0.18^{\mathrm{cA}}$ \\
\hline & & $\mathrm{V}$ & $8.94 \pm 0.03^{\mathrm{dB}}$ & $8.32 \pm 0.05^{\mathrm{dC}}$ & $10.23 \pm 0.26^{\mathrm{bA}}$ & $10.63 \pm 0.61^{\mathrm{cbA}}$ & $10.26 \pm 0.06^{\mathrm{bA}}$ \\
\hline & & US-SH & $4.57 \pm 0.47^{\mathrm{fC}}$ & $6.49 \pm 0.91^{\mathrm{eB}}$ & $7.09 \pm 0.99^{\mathrm{cBA}}$ & $5.88 \pm 0.55^{\mathrm{edBC}}$ & $8.15 \pm 1.19^{\mathrm{dcA}}$ \\
\hline & & $\mathrm{M}-\mathrm{SH}$ & $8.84 \pm 0.25^{\mathrm{dC}}$ & $9.78 \pm 0.51^{\mathrm{cB}}$ & $11.19 \pm 0.12^{\mathrm{bA}}$ & $10.13 \pm 0.16^{\mathrm{cB}}$ & $8.28 \pm 0.17^{\mathrm{dcD}}$ \\
\hline & & $\mathrm{SH}$ & $11.04 \pm 1.92^{\mathrm{bB}}$ & $13.19 \pm 0.15^{\mathrm{aA}}$ & $10.18 \pm 1.29^{\mathrm{bB}}$ & $9.91 \pm 0.71^{\mathrm{cB}}$ & $13.23 \pm 0.18^{\mathrm{aA}}$ \\
\hline & $\xi$ & $\mathrm{V}$ & $10.17 \pm 0.06^{\mathrm{bcA}}$ & $11.58 \pm 0.86^{\mathrm{bA}}$ & $10.29 \pm 0.92^{\mathrm{bA}}$ & $11.57 \pm 0.95^{\mathrm{bA}}$ & $10.72 \pm 0.28^{\mathrm{bA}}$ \\
\hline & & US-SH & $5.67 \pm 0.21^{\mathrm{fBA}}$ & $7.17 \pm 1.40^{\mathrm{edA}}$ & $6.71 \pm 1.77^{\mathrm{cBA}}$ & $4.76 \pm 1.23^{\mathrm{eB}}$ & $7.54 \pm 0.49^{\mathrm{dA}}$ \\
\hline & & M-SH & $13.44 \pm 0.23^{\mathrm{aA}}$ & $13.29 \pm 0.08^{\mathrm{aBA}}$ & $13.36 \pm 0.23^{\mathrm{aA}}$ & $12.85 \pm 0.29^{\mathrm{aB}}$ & $10.46 \pm 0.27^{\mathrm{bC}}$ \\
\hline \multirow{8}{*}{$\mathrm{b}^{*}$} & $\stackrel{N}{0}$ & $\mathrm{SH}$ & $47.87 \pm 0.74^{\mathrm{dA}}$ & $49.18 \pm 1.35^{\text {baA }}$ & $48.12 \pm 1.47^{\mathrm{aA}}$ & $42.14 \pm 0.80^{\mathrm{aB}}$ & $30.54 \pm 0.95^{\mathrm{dC}}$ \\
\hline & & V & $50.26 \pm 0.28^{\mathrm{bA}}$ & $50.45 \pm 0.12^{\mathrm{baA}}$ & $47.56 \pm 0.16^{\mathrm{aB}}$ & $41.82 \pm 2.04^{\mathrm{aC}}$ & $29.24 \pm 0.31^{\mathrm{dD}}$ \\
\hline & & US-SH & $50.27 \pm 2.95^{\mathrm{bA}}$ & $50.53 \pm 0.91^{\text {baA }}$ & $47.27 \pm 1.45^{\mathrm{aA}}$ & $40.42 \pm 2.43^{\mathrm{aB}}$ & $36.45 \pm 1.03^{\mathrm{bC}}$ \\
\hline & & M-SH & $54.02 \pm 0.93^{\mathrm{aA}}$ & $51.78 \pm 0.47^{\mathrm{aB}}$ & $45.54 \pm 0.45^{\mathrm{aC}}$ & $39.79 \pm 0.64^{\mathrm{baD}}$ & $29.56 \pm 0.49^{\mathrm{dE}}$ \\
\hline & & $\mathrm{SH}$ & $43.34 \pm 1.06^{\mathrm{eB}}$ & $47.23 \pm 0.09^{\mathrm{bcA}}$ & $39.22 \pm 2.36^{\mathrm{bC}}$ & $36.15 \pm 0.06^{\mathrm{dcD}}$ & $33.54 \pm 0.30^{\mathrm{cE}}$ \\
\hline & $\dot{\Sigma}$ & $\mathrm{V}$ & $47.65 \pm 0.33^{\mathrm{cdA}}$ & $45.75 \pm 0.87^{\mathrm{cA}}$ & $41.34 \pm 3.63^{\mathrm{bB}}$ & $37.10 \pm 1.22^{\mathrm{bcC}}$ & $33.28 \pm 2.01^{\mathrm{cD}}$ \\
\hline & it & US-SH & $49.47 \pm 0.54^{\mathrm{cbA}}$ & $45.09 \pm 4.64^{\mathrm{cBA}}$ & $41.09 \pm 3.04^{\mathrm{bBC}}$ & $36.01 \pm 2.32^{\mathrm{dcC}}$ & $38.41 \pm 0.10^{\mathrm{aC}}$ \\
\hline & 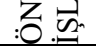 & M-S & $46.23 \pm 0.32^{\mathrm{dA}}$ & $41.70 \pm 0.28^{\mathrm{dB}}$ & $39.05 \pm 0.14^{\mathrm{bC}}$ & $33.71 \pm 1.16^{\mathrm{dD}}$ & $30.38 \pm 0.80^{\mathrm{dE}}$ \\
\hline \multirow{8}{*}{ Kroma } & $\bar{N}$ & $\mathrm{SH}$ & $48.38 \pm 0.74^{\mathrm{cA}}$ & $49.44 \pm 1.26^{\text {bacA }}$ & $48.45 \pm 1.44^{\mathrm{aA}}$ & $42.63 \pm 0.78^{\mathrm{aB}}$ & $31.77 \pm 0.97^{\mathrm{dC}}$ \\
\hline & $\approx$ & $\mathrm{V}$ & $51.05 \pm 0.28^{\mathrm{bA}}$ & $51.13 \pm 0.11^{\text {baA }}$ & $48.65 \pm 0.21^{\mathrm{aB}}$ & $43.16 \pm 1.97^{\mathrm{aC}}$ & $30.99 \pm 0.27^{\mathrm{dD}}$ \\
\hline & & US-SH & $50.48 \pm 2.93^{\mathrm{cbA}}$ & $50.95 \pm 1.01^{\text {baA }}$ & $47.81 \pm 1.42^{\mathrm{aA}}$ & $40.85 \pm 2.37^{\mathrm{baB}}$ & $37.36 \pm 0.87^{\mathrm{bC}}$ \\
\hline & & $\mathrm{M}-\mathrm{SH}$ & $54.74 \pm 0.89$ aA & $52.70 \pm 0.50^{\mathrm{aB}}$ & $46.89 \pm 0.41^{\mathrm{aC}}$ & $41.05 \pm 0.63^{\mathrm{baD}}$ & $30.70 \pm 0.43^{\mathrm{dE}}$ \\
\hline & 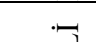 & $\mathrm{SH}$ & $44.74 \pm 1.43^{\mathrm{dB}}$ & $48.98 \pm 0.08^{\mathrm{bcA}}$ & $40.54 \pm 2.28^{\mathrm{bC}}$ & $37.49 \pm 0.15^{\mathrm{cD}}$ & $36.06 \pm 0.34^{\mathrm{cbD}}$ \\
\hline & $\sum$ & $\mathrm{V}$ & $48.72 \pm 0.33^{\mathrm{cbA}}$ & $47.19 \pm 1.05^{\mathrm{dcA}}$ & $42.62 \pm 3.32^{\mathrm{bB}}$ & $38.87 \pm 1.45^{\mathrm{bcC}}$ & $34.96 \pm 1.93^{\mathrm{cD}}$ \\
\hline & & US-SH & $49.79 \pm 0.52^{\mathrm{cbA}}$ & $45.67 \pm 4.67^{\mathrm{edBA}}$ & $41.64 \pm 3.27^{\mathrm{bBC}}$ & $36.34 \pm 2.14^{\mathrm{cD}}$ & $39.15 \pm 0.19^{\mathrm{aDC}}$ \\
\hline & & $\mathrm{M}-\mathrm{SH}$ & $48.14 \pm 0.26^{\mathrm{cA}}$ & $43.76 \pm 0.24^{\mathrm{eB}}$ & $41.27 \pm 0.20^{\mathrm{bC}}$ & $36.08 \pm 1.03^{\mathrm{cD}}$ & $32.13 \pm 0.84^{\mathrm{dE}}$ \\
\hline \multirow{8}{*}{ Hue açısı } & $\underline{N}$ & $\mathrm{SH}$ & $81.57 \pm 0.08^{\mathrm{bB}}$ & $84.16 \pm 1.08^{\mathrm{aA}}$ & $83.30 \pm 0.51^{\mathrm{aA}}$ & $81.34 \pm 0.25^{\mathrm{aB}}$ & $73.95 \pm 0.18^{\mathrm{cC}}$ \\
\hline & & $\mathrm{V}$ & $79.90 \pm 0.03^{\mathrm{cA}}$ & $80.62 \pm 0.07^{\mathrm{dcA}}$ & $77.86 \pm 0.26^{\mathrm{cB}}$ & $75.71 \pm 1.12^{\mathrm{bC}}$ & $70.66 \pm 0.30^{\mathrm{dD}}$ \\
\hline & & US-SH & $84.78 \pm 0.61^{\mathrm{aA}}$ & $82.68 \pm 0.89^{\mathrm{bBA}}$ & $81.46 \pm 1.23^{\mathrm{baB}}$ & $81.68 \pm 1.05^{\mathrm{aB}}$ & $77.37 \pm 2.00^{\mathrm{bC}}$ \\
\hline & & $\mathrm{M}-\mathrm{SH}$ & $80.69 \pm 0.38^{\mathrm{cbA}}$ & $79.29 \pm 0.52^{\mathrm{dB}}$ & $76.19 \pm 0.26^{\mathrm{cC}}$ & $75.71 \pm 0.26^{\mathrm{bC}}$ & $74.34 \pm 0.56^{\mathrm{cD}}$ \\
\hline & ] & $\mathrm{SH}$ & $.15^{\mathrm{eA}}$ & $74.39 \pm 0.15^{\mathrm{eA}}$ & $04^{\mathrm{CA}}$ & $74.67 \pm 1.06^{\mathrm{cbA}}$ & $=0.10^{\mathrm{eB}}$ \\
\hline & $\theta$ & $\mathrm{V}$ & $77.95 \pm 0.03 \mathrm{dA}$ & $75.79 \pm 0.76^{\mathrm{eA}}$ & $75.90 \pm 2.37^{\mathrm{cA}}$ & $72.69 \pm 0.80^{\mathrm{cB}}$ & $72.10 \pm 1.06^{\mathrm{dB}}$ \\
\hline & 4 & US-SH & $83.45 \pm 0.27^{\mathrm{aA}}$ & $80.95 \pm 1.65^{\mathrm{cBA}}$ & $80.80 \pm 1.79^{\mathrm{bBA}}$ & $82.37 \pm 2.42^{\mathrm{aA}}$ & $78.89 \pm 0.68^{\mathrm{aB}}$ \\
\hline & & $\mathrm{M}-\mathrm{SH}$ & $73.78 \pm 0.35^{\mathrm{fA}}$ & $72.32 \pm 0.22^{\mathrm{fB}}$ & $71.11 \pm 0.26^{\mathrm{dC}}$ & $69.11 \pm 0.97^{\mathrm{dD}}$ & $71.00 \pm 0.13^{\mathrm{dC}}$ \\
\hline \multirow{8}{*}{ TRD } & N & SH & $9.94 \pm 0.83^{\mathrm{cD}}$ & $11.96 \pm 0.39^{\mathrm{bCB}}$ & $10.85 \pm 0.38^{\mathrm{cCD}}$ & $12.69 \pm 0.78^{\mathrm{dB}}$ & $25.54 \pm 1.14^{\text {bcA }}$ \\
\hline & & V & $10.38 \pm 0.25^{\mathrm{cC}}$ & $7.73 \pm 0.77^{\mathrm{CD}}$ & $10.28 \pm 0.28^{\mathrm{cC}}$ & $14.22 \pm 2.12^{\mathrm{dcB}}$ & $27.77 \pm 0.44^{\mathrm{aA}}$ \\
\hline & & US-SH & $8.37 \pm 0.38^{\mathrm{eC}}$ & $7.66 \pm 0.97^{\mathrm{cC}}$ & $9.54 \pm 0.67^{\mathrm{cC}}$ & $14.52 \pm 2.00^{\mathrm{dcB}}$ & $18.24 \pm 1.23^{\mathrm{dA}}$ \\
\hline & & M-SH & $6.56 \pm 0.26^{\mathrm{fE}}$ & $7.96 \pm 0.40^{\mathrm{cD}}$ & $11.31 \pm 0.40^{\mathrm{bcC}}$ & $15.63 \pm 0.52^{\mathrm{cB}}$ & $26.00 \pm 0.65^{\text {baA }}$ \\
\hline & & $\mathrm{SH}$ & $13.90 \pm 0.54^{\mathrm{aD}}$ & $12.17 \pm 0.14^{\mathrm{bD}}$ & $16.35 \pm 2.26^{\mathrm{aC}}$ & $19.29 \pm 0.19^{\mathrm{bB}}$ & $24.59 \pm 0.10^{\mathrm{bcA}}$ \\
\hline & $=$ & $\mathrm{V}$ & $9.12 \pm 0.21^{\mathrm{dC}}$ & $11.49 \pm 0.09^{\mathrm{bCB}}$ & $14.93 \pm 3.89^{\mathrm{baB}}$ & $20.06 \pm 0.75^{\mathrm{bA}}$ & $23.54 \pm 2.48^{\mathrm{cA}}$ \\
\hline & & US-SH & $10.46 \pm 0.06^{\mathrm{cC}}$ & $12.51 \pm 3.90^{\mathrm{bBC}}$ & $15.59 \pm 3.95^{\mathrm{aB}}$ & $20.90 \pm 1.43^{\mathrm{bA}}$ & $16.69 \pm 0.11^{\mathrm{dBA}}$ \\
\hline & : 0.0 & M-SH & $12.54 \pm 0.36^{\mathrm{bE}}$ & $15.89 \pm 0.30^{\mathrm{aD}}$ & $18.79 \pm 0.31^{\mathrm{aC}}$ & $24.39 \pm 0.96^{\mathrm{aB}}$ & $25.97 \pm 1.07^{\mathrm{baA}}$ \\
\hline
\end{tabular}

*Aynı sütundaki farklı üstel küçük harflerle aynı satırdaki farklı üstel büyük harfler ortalamaların $p<0.05$ seviyesinde farklı olduğunu gösterir $(\mathrm{n}=3)$.

Kurutulmuş kamkat dilimlerinin $b^{*}$ değerleri üzerine depolama süresi içerisinde varyasyon kaynaklarının etkisi önemli $(p<0.001 ; p<0.05)$ bulunmuştur (Çizelge 2). Depolamanın başlangıcında en yüksek $b^{*}$ değeri ön işlemsiz M-SH yönteminde belirlenmiştir. Depolama süresi boyunca tüm uygulamalarda \%22.61-45.28 oranları arasında azalış göstermiştir. b* değerindeki en yüksek azalış oranı ön işlemsiz $\mathrm{M}-\mathrm{SH}$, en düşük azalış oranı ise ön işlemli SH yöntemiyle kurutulan örneklerde gerçekleşmiştir. Depolama sonunda en yüksek $b^{*}$ değeri ön işlemli US-SH yöntemi ile kurutulan örneklerde tespit edilmiştir. 
Varyasyon kaynaklarının örneklerin kroma değerleri üzerine etkisi önemli olup (Çizelge 2), kroma değerleri tüm uygulamalarda \%19.40-43.91 oranları arasında azalış göstermiştir. Kroma değerindeki en yüksek azalış oranı ön işlemsiz M-SH, en düşük azalış oranı ise ön işlemli SH yöntemiyle kurutulan örneklerde gerçekleşmiştir. Depolama sonunda en yüksek kroma değeri ön işlemli US-SH yöntemi ile kurutulan örnekte belirlenmiştir.

Ön işlem x kurutma yöntemi x depolama süresi interaksiyonu dışında diğer varyasyon kaynaklarının depolama süresinde örneklerin hue açısı ve TRD değerlerine etkisi önemli bulunmuştur (Çizelge 2). Hue açısı değerleri tüm kurutma uygulamalarında \% 3.76-11.56 oranları arasında azalış göstermiştir. $(p<0.05)$. En yüksek azalış oranı ön işlemsiz V, en düşük azalış oranı ise ön işlemli M-SH yöntemiyle kurutulan örneklerde gerçekleşmiştir. Depolama süresinin sonunda en yüksek hue açısı değeri ön işlemli US-SH yönteminde belirlenmiştir.

Depolama sonunda en yüksek TRD değeri ön işlemsiz V yöntemi ile kurutulan örneklerde belirlenirken, TRD değerleri tüm uygulamalarda başlangıca göre depolama sonunda 0.59-2.96 kat artış göstermiş̧tir. En düşük artı̧̧ ön işlemli US-SH, en yüksek artış ise ön işlemsiz M-SH yönteminde gerçekleşmiş̧tir.

\subsection{HMF içeriğindeki değişimler}

Farklı kurutma yöntemleri ile ön işlemli ve ön işlemsiz kurutulan kamkat dilimlerinin depolama süresine bağlı olarak HMF değişimi Çizelge 5'te verilmiştir. Varyasyon kaynaklarının kurutulmuş kamkat dilimlerinin depolama süresi boyunca HMF miktarlarına etkisi $p<0.001$ düzeyinde önemli bulunmuştur (Çizelge 2). Depolama süresi içerisinde genel olarak ön işlemsiz örneklerin HMF değerleri, ön işlemli örneklerden yüksek bulunmuştur $(p<0.05)$. Ön işlem olarak kullanılan haşlama işlemiyle birlikte HMF’nin oluşumunda yer alan indirgen şekerlerin kısmen azaldığı düşünülmektedir.

Depolamanın başlangıcında HMF değerleri $0.39-12.33 \mathrm{mg} / \mathrm{kg}$ arasında olup, depolama sonunda $2.02-46.79 \mathrm{mg} / \mathrm{kg}$ değerlerine yükselmiştir. Depolamanın sürecinde genel olarak en yüksek HMF içeriği ön işlemsiz V ile kurutulan örneklerde, en düşük HMF içeriği ise ön işlemli US-SH yöntemi ile kurutulan örneklerde tespit edilmiş̧ir. Depolama süresi boyunca örneklerin HMF değerleri tüm örneklerde 2.66-7.17 kat arasında artış göstermiştir ( $p<0.05)$, En yüksek artış ön işlemsiz US-SH, en düşük artış ise ön işlemsiz M-SH yönteminde gerçekleşmiştir.

Çizelge 5. Farklı yöntemlerle ön işlemli ve ön işlemsiz kurutulmuş kamkat dilimlerinin depolama sürecinde HMF (mg/kg) değişimi.

\begin{tabular}{|c|c|c|c|c|c|c|}
\hline \multirow{2}{*}{\multicolumn{2}{|c|}{ Kurutma Yöntemleri }} & \multicolumn{5}{|c|}{ Depolama süresi (Ay) ${ }^{*}$} \\
\hline & & 0. & 1. & 2. & 3. & 4. \\
\hline \multirow{4}{*}{ 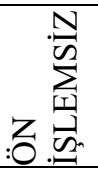 } & $\mathrm{SH}$ & $7.80 \pm 0.10^{\mathrm{cE}}$ & $20.48 \pm 0.27^{\mathrm{bD}}$ & $23.33 \pm 1.25^{\mathrm{bC}}$ & $32.64 \pm 1.21^{\mathrm{aB}}$ & $34.74 \pm 1.35^{\mathrm{cbA}}$ \\
\hline & $\mathrm{V}$ & $12.33 \pm 1.56^{\mathrm{aC}}$ & $24.97 \pm 0.64^{\mathrm{aB}}$ & $25.75 \pm 0.32^{\mathrm{aB}}$ & $25.98 \pm 1.47^{\mathrm{bB}}$ & $46.79 \pm 2.11^{\mathrm{aA}}$ \\
\hline & US-SH & $1.52 \pm 0.23^{\mathrm{eD}}$ & $3.32 \pm 0.73^{\mathrm{fC}}$ & $5.26 \pm 0.37^{\mathrm{fB}}$ & $6.06 \pm 0.58^{\mathrm{dB}}$ & $12.42 \pm 0.53^{\mathrm{eA}}$ \\
\hline & M-SH & $9.97 \pm 0.69^{\mathrm{bE}}$ & $12.69 \pm 1.31^{\mathrm{cD}}$ & $15.37 \pm 0.60^{\mathrm{dC}}$ & $25.50 \pm 1.68^{\mathrm{bB}}$ & $36.53 \pm 1.78^{\mathrm{cbA}}$ \\
\hline \multirow{4}{*}{ 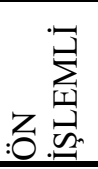 } & $\mathrm{SH}$ & $4.57 \pm 0.61^{\mathrm{dE}}$ & $7.45 \pm 0.64^{\mathrm{eD}}$ & $11.49 \pm 1.23^{\mathrm{eC}}$ & $23.82 \pm 0.62^{\mathrm{cbB}}$ & $30.85 \pm 0.32^{\mathrm{dA}}$ \\
\hline & $\mathrm{V}$ & $5.67 \pm 0.56^{\mathrm{dD}}$ & $6.39 \pm 0.29^{\mathrm{eD}}$ & $12.51 \pm 0.28^{\mathrm{eC}}$ & $25.74 \pm 1.21^{\mathrm{bB}}$ & $33.25 \pm 3.19^{\mathrm{cdA}}$ \\
\hline & US-SH & $0.39 \pm 0.02^{\mathrm{eE}}$ & $0.57 \pm 0.04^{\mathrm{gD}}$ & $0.79 \pm 0.06^{\mathrm{gC}}$ & $1.48 \pm 0.07^{\mathrm{eB}}$ & $2.02 \pm 0.05^{\mathrm{fA}}$ \\
\hline & $\mathrm{M}-\mathrm{SH}$ & $7.59 \pm 0.40^{\mathrm{cE}}$ & $11.31 \pm 0.97^{\mathrm{dD}}$ & $17.21 \pm 0.69^{\mathrm{cC}}$ & $23.17 \pm 1.58^{\mathrm{cB}}$ & $37.27 \pm 2.72^{\mathrm{bA}}$ \\
\hline
\end{tabular}

*Aynı sütundaki farklı üstel küçük harflerle aynı satırdaki farklı üstel büyük harfler ortalamaların $p<0.05$ seviyesinde farklı olduğunu gösterir $(\mathrm{n}=3)$.

\subsection{Askorbik asit içeriğindeki değişimler}

Farklı kurutma yöntemleri ile ön işlemli ve ön işlemsiz kurutulan kamkat dilimlerinin depolama süresine bağlı olarak askorbik asit değişimi Çizelge 6'da verilmiştir. Varyasyon kaynaklarının kurutulmuş kamkat dilimlerinin depolama süresi boyunca askorbik asit miktarlarına etkisi $p<0.001$ düzeyinde önemli bulunmuştur (Çizelge 2). 
Çizelge 6. Farklı yöntemlerle ön işlemli ve ön işlemsiz kurutulmuş kamkat dilimlerinin depolama sürecinde askorbik asit içeriklerinin değişimi (mg/100 g).

\begin{tabular}{|c|c|c|c|c|c|c|}
\hline \multirow{2}{*}{\multicolumn{2}{|c|}{ Kurutma Yöntemleri }} & \multicolumn{5}{|c|}{ Depolama süresi (Ay) ${ }^{*}$} \\
\hline & & 0. & 1. & 2. & 3. & 4. \\
\hline \multirow{4}{*}{ 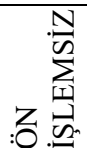 } & $\mathrm{SH}$ & $233.29 \pm 2.71^{\mathrm{bA}}$ & $216.56 \pm 1.35^{\mathrm{bB}}$ & $175.42 \pm 2.46^{\mathrm{bC}}$ & $158.38 \pm 0.82^{\mathrm{bD}}$ & $141.92 \pm 1.45^{\mathrm{bE}}$ \\
\hline & $\mathrm{V}$ & $281.00 \pm 1.47^{\mathrm{aA}}$ & $233.90 \pm 2.26^{\mathrm{aB}}$ & $234.34 \pm 1.88^{\mathrm{aB}}$ & $229.85 \pm 0.81^{\mathrm{aC}}$ & $175.01 \pm 1.07^{\mathrm{aD}}$ \\
\hline & US-SH & $162.61 \pm 0.63^{\mathrm{dA}}$ & $154.55 \pm 0.50^{\mathrm{dB}}$ & $129.57 \pm 0.52^{\mathrm{dC}}$ & $123.16 \pm 0.41^{\mathrm{dD}}$ & $116.49 \pm 0.62^{\mathrm{cE}}$ \\
\hline & $\mathrm{M}-\mathrm{SH}$ & $195.56 \pm 2.78 \mathrm{cA}$ & $157.33 \pm 0.86^{\mathrm{cB}}$ & $138.22 \pm 0.82^{\mathrm{cC}}$ & $127.11 \pm 0.45^{\mathrm{cD}}$ & $96.78 \pm 1.20^{\mathrm{dE}}$ \\
\hline \multirow{4}{*}{ 寻 } & $\mathrm{SH}$ & $128.56 \pm 0.60^{\mathrm{eA}}$ & $117.33 \pm 1.17^{\mathrm{fB}}$ & $107.63 \pm 1.02^{\mathrm{eC}}$ & $100.63 \pm 0.63^{\mathrm{eD}}$ & $67.34 \pm 0.29^{\mathrm{fE}}$ \\
\hline & $\mathrm{V}$ & $123.53 \pm 1.04^{\mathrm{fA}}$ & $121.65 \pm 1.14^{\mathrm{eA}}$ & $93.80 \pm 2.47^{\mathrm{fB}}$ & $87.50 \pm 0.35^{\mathrm{fC}}$ & $74.48 \pm 0.66^{\mathrm{eD}}$ \\
\hline & US-SH & $45.88 \pm 0.83 \mathrm{hA}$ & $40.14 \pm 0.34^{\mathrm{hB}}$ & $36.69 \pm 0.44^{\mathrm{hC}}$ & $17.33 \pm 1.08^{\mathrm{hD}}$ & $11.19 \pm 0.43^{\mathrm{hE}}$ \\
\hline & M-SH & $70.46 \pm 0.22 \mathrm{gA}$ & $51.84 \pm 0.31^{\mathrm{gB}}$ & $39.59 \pm 1.60^{\mathrm{gC}}$ & $36.31 \pm 0.23^{\mathrm{gD}}$ & $24.24 \pm 0.91^{\mathrm{gE}}$ \\
\hline
\end{tabular}

*Aynı sütundaki farklı üstel küçük harflerle aynı satırdaki farklı üstel büyük harfler ortalamaların $p<0.05$ seviyesinde farklı olduğunu gösterir $(\mathrm{n}=3)$.

Depolama süresinde ön işlemsiz örneklerin askorbik asit değerleri ön işlemli örneklerden yüksek bulunmuştur. Ön işlemli kurutulmuş örneklerin başlangıç askorbik asit miktarlarının da düşük olduğu görülmektedir. Depolama süresi boyunca en yüksek askorbik asit içeriği ön işlemsiz V, en düşük askorbik asit içeriği ise ön işlemli US-SH yöntemi ile kurutulan örneklerde tespit edilmiştir $(p<0.05)$. Depolama süresi boyunca kurutulmuş örneklerin askorbik asit içeriğinde \%28.36-75.61 oranında kayıplar meydana gelmiştir $(p<0.05)$. En yüksek askorbik asit kaybı ön işlemli US-SH, en düşük askorbik asit kaybı ise ön işlemsiz US-SH yönteminde tespit edilmiştir.

\section{Tartışma ve Sonuç}

Kamkat dilimlerinin ön işlemli olarak kurutulması depolama süresi içerisinde su aktivitesi ve nem içeriğini olumsuz etkilemiştir. Ön işlem olarak uygulanan haşlama işlemi ile birlikte su bağlama yeteneğine sahip bazı maddelerin kaybı bu durumu etkilemiş olabilir. Suda çözünür maddelerin yanında, nişasta ve proteinler gibi çözünebilir nitelikte olmayan bazı makro moleküllerin su bağlayabilme özellikleri nedeniyle su aktivitesinin düşmesinde rol oynadıkları bilinmektedir (Cemeroğlu ve ark., 2003; Us, 2007). Bu durumun da ön işlemli kurutulan örneklerin daha fazla nem çekmesine dolayısıyla $\mathrm{a}_{\mathrm{w}}$ artışına neden olduğu düşünülmektedir. Kurutma teknoloji açısından suyun buhar basıncına etkili bir faktör de kapilar kuvvetin etkisidir. Kurumada gıda maddelerindeki su, hücreler arasında oluşmuş bir kapilar sistemle yüzeye ulaşarak buradan uzaklaşmaktadır. Buna bağlı olarak kurutma sırasında meyve ve sebzelerde hücreler arasındaki kapilar yapı değișebilmektedir. (Cemeroğlu ve ark., 2003). Bunun yanında depolamanın yapıldığı polietilen torbalar belli oranda nem geçirgenliğine sahip olabilmektedir (Topuz ve ark., 2009). Ozmotik dehidrasyon sonrası sicak hava kurutma ile kurutulan papaya meyvelerinin farklı ambalaj materyalleri ile depolanması sonucu nem ve su aktivitesinde artış gözlenmiştir (Udomkun ve ark., 2016). Mikroorganizmalar genel olarak $\mathrm{a}_{\mathrm{w}}$ değeri 0.60 'ın altında gelişme olanağı bulamazlar. Patojen bakteriler 0.85 , maya ve küfler ise 0.62 su aktivite değerinin altında gelişemez. (Rahman, 2007). Diğer yandan enzimatik olmayan esmerleşme reaksiyonlarından Maillard reaksiyonlarının hızı $\mathrm{a}_{\mathrm{w}}$ 0.65-0.80 arasında en üst seviyeye ulaşmaktadır (Pala ve Saygı, 1983). Her ne kadar örneklerde 4 aylık depolama periyodundaki $\mathrm{a}_{\mathrm{w}}$ artış1 olsa da bu artışlar gerek mikrobiyal faaliyetler gerekse enzimatik olmayan esmerleşme reaksiyonlarını tetikleyecek seviyeye ulaşmamıştır.

Depolama ile birlikte $\mathrm{L}^{*}, \mathrm{~b}^{*}$, kroma, hue açısı değerleri azalış göstermiş, $\mathrm{a}^{*}$ ve TRD değerleri ise artış göstermiştir. $\mathrm{L}^{*}$ değerindeki azalış ve $\mathrm{a}^{*}$ değerindeki artış esmerleşme reaksiyonlarına işaret etmektedir (Krokida ve Maroulis, 2000; Ghanem ve ark., 2012). b* değerinin azalması sarılıktan uzaklaşma anlamına gelip, bu durumun depolama sürecinde karotenoidlerin oksidasyona bağlı olarak parçalanmasından kaynaklanabileceği düşünülmektedir (Topuz ve ark., 2009; Darvishi ve ark., 2014; Ghanem Romdhane ve ark., 2015). Hawlader et al. (2006), hue açısı değerlerindeki düşüşün, kahverengileşmenin ve sarılıktan uzaklaşmanın bir göstergesi olduğunu belirtmiştir. Hue açısı değerinin $0^{\circ}$ olması kırmızı, $90^{\circ}$ olması sarı, $180^{\circ}$ olması yeşil ve $270^{\circ}$ olması mavi renk tonların ifade etmektedir (Veberic ve ark., 2010). Ön işlemli olarak US-SH yöntemi ile kurutulan kamkat dilimlerinin depolama süresinin sonunda taze meyvenin renk değerlerine en yakın değerlerde olduğu tespit edilmiştir. Esmerleşme reaksiyonlarından Maillard reaksiyonunun oluşumunda indirgen şekerler önemli bir rol oynamaktadır (Michalska ve ark., 2018). Haşlama ve ultrason destekli ozmotik dehidrasyon sırasında 
indirgen şeker gibi suda çözünebilir bileşenler kayba uğrayabilmektedir. (Gonzalez-Fesler ve ark., 2008; Gonçalves ve ark., 2010; Chavan ve Amarowicz 2012; Wang ve ark., 2017). Çalışmamızda ön işlemli US-SH yönteminde uygulanan haşlama ve ultrason destekli ozmotik dehidrasyon işlemindeki indirgen şeker kaybının kurutma ve depolama sırasında renk kayıplarını kısmen engellediği düşünülmektedir. HMF 1sıl işlem görmüş çeşitli gıda maddelerinin gerek üretimi gerekse depolanması sırasında ortaya çıkan ve bu ürünlerin kalitesinin belirlenmesinde kullanılan önemli bir göstergedir (Michalska ve ark., 2018). Isıl işlem görmüş gıda maddelerinin su aktivitesi, nem içeriği, depolama süresi ve sıcaklığı HMF oluşumunu etkilemektedir (Toker ve ark., 2013; Touati ve ark., 2014; Udomkun ve ark., 2016). Türk Gıda Kodeksi'nde (TGK) kurutulmuş meyvelerle ilgili HMF limiti bulunmamaktadır. Ancak TGK bal tebliği (Tebliğ No:2012/58) HMF limiti $40 \mathrm{mg} / \mathrm{kg}$ iken, TGK üzüm pekmezi tebliğinde (Teblĭg No:2017/8) ise bu miktar $75 \mathrm{mg} / \mathrm{kg}$ ile sınırlandırılmıştır. Kurutulmuş kamkat dilimlerinin HMF içerikleri depolama süresinde artış göstermiş, ancak söz konusu değerler mevzuat limitlerini aşmamıştır. Farklı ambalajlama materyali ve depolama süresinin kurutulmuş papayanın fonksiyonel özelliklerine etkisinin araştırıldığı çalışmada, 9 aylık depolama süresinde HMF içeriğinde artış gerçekleştiği tespit edilmiştir. (Udomkun ve ark., 2016).

Askorbik asit meyve ve sebzelerin depolama ve işleme süreçlerinde besin kayıplarının değerlendirilmesinde kullanılan önemli bir indikatördür. Gıdalarda askorbik asit stabilitesi sıcaklık, $\mathrm{pH}$, oksijen, 1şık, metal iyonları, su aktivitesi gibi faktörlere göre değişiklik göstermektedir (Santos ve Silva, 2008; Wang ve ark., 2018). Depolama süresi özellikle ön işlemli kurutulmuş örneklerin askorbik asit içeriğini olumsuz etkilemiştir. Depolama sürecinde en yüksek askorbik asit içeriğine sahip örneklerin V yönteminde tespit edilmiş olmasının sebebi bu yöntemde kurutma esnasında ortamda bulunan düşük seviyedeki oksijen seviyesidir (Sablani, 2006). En fazla oranda askorbik asit kaybının belirlendiği ön işlemli US-SH yönteminde, ön işlem olarak kullanılan haşlama işlemi, hücre yapısının bozulmasına, dolayısıyla askorbik asitin hızlı oksidasyonuna sebep olarak depolama sürecinde daha fazla kayba neden olmuş olabilir. Ayrıca, askorbik asit suda çözünebilir bir bileşen olduğu için haşlama ve ozmotik dehidrasyon sirasındaki kütle transferi sırasında kayba uğrayabilmektedir (Santos ve Silva, 2008). Udomkun ve ark. (2016) depolama sırasında askorbik asit parçalanmasının su aktivitesi ve nem içeriği ile ilişkili olabileceğini bildirmiş̧tir. Söz konusu örnek aynı zamanda depolama sırasında en fazla nem artışının gerçekleştiği örnektir. Depolama sırasında kurutma ve depolama koşullarına bağlı olarak kurutulmuş ürünlerde askorbik asit içeriğinde kayıplar meydana gelebilmektedir (Uddin ve ark., 2002; Del Caro ve ark., 2004; Udomkun ve ark., 2016).

Bu çalışmada suda haşlama işlemi uygulanmış ve ön işlemsiz olarak farklı kurutma yöntemleri ile kurutulmuş kamkat dilimlerinin depolama süresinde bazı kalite değişimleri incelenmiştir. 4 aylık depolama süresinde incelenen kriterler üzerine ön işlemin, kurutma yöntemlerinin ve depolama süresinin etkisi önemli bulunmuştur. Çalışma sonucunda, kamkat dilimlerinin tüm kurutma yöntemleri için ön işlemsiz kurutularak depolanmasının incelenen kalite kriterleri açısından daha iyi sonuçlar verdiği belirlenmiştir. Depolama stabilitesi açısından farklı depolama koşulları ile ambalaj materyallerinin kurutulmuş kamkat dilimlerinin kalitesi üzerine etkilerinin araştırılacağı daha fazla çalışmaya ihtiyaç duyulmaktadır.

\section{Teşekkür}

Bu çalışma Farklı Yöntemlerle Kurutulmuş Kamkatın (Fortunella margarita Swing.) Bazı Kalite Özellikleri ve Depolamaya Bağlı Değiş̧imi” adlı doktora tezinin bir kısmıdır. Çalışmayı Doktora Burs Programı kapsamında destekleyen TÜBİTAK-BİDEB'e teşekkürlerimizi sunarız.

\section{Kaynakça}

Akdaş, S., \& Başlar, M. (2015). Dehydration and degradation kinetics of bioactive compounds for mandarin slices under vacuum and oven drying conditions. J. Food Process. Preserv., 39(6), 1098-1107.

AOAC, (2000). 17th Edi 2000 Official Method 986.21. Moisture in Spices / IS specification No. IS 1797-1985; Methods of Test for Spices and Condiments.

Cemeroğlu, B., Karadeniz, F., \& Özkan, M. (2003). Meyve ve Sebze İşleme Teknolojisi. Gida Teknolojisi Derneği Yayınları No:28, Ankara. 690 s. 
Cemeroğlu, B. (2007). Gıda analizleri. Gıda Teknolojisi Derneği Yayınları, Ankara, 535 s.

Chavan, U. D., \& Amarowicz, R. (2012). Osmotic dehydration process for preservation of fruits and vegetables. Journal of Food Research, 1(2), 202.

Chen, H. H., Hernandez, C. E., \& Huang, T. C. (2005). A study of the drying effect on lemon slices using a closed-type solar dryer. Solar Energy, 78(1), 97-103.

Chiu, N. C., \& Chang, K. S. (1998). The Illustrated Medicinal Plants of Taiwan. Taiwan: SMC publishing Ltd, Vol 5, Taipei, Taiwan, 194 p.

Darvishi, H., Khoshtaghaza, M.H., \& Minaei, S. (2014). Drying kinetics and colour change of lemon slices. Internatıonal Agrophysics, 28,1-6.

Del Caro, A., Piga, A., Pinna, I. P., Fenu, M., \& Agabbio, M. (2004). Effect of drying conditions and storage period on polyphenolic content. antioxidant capacity. and ascorbic acid of prunes. Journal of Agricultural and Food Chemistry, 52(15), 4780-4784.

Di Scala, K. C., \& Crapiste, G. H. (2008). Drying kinetics and quality changes during drying of red pepper. LWT Food Science and Technology, 41(5), 789-795.

Doymaz, İ. (2007). Air-drying characteristics of tomatoes. J. of Food Engineering, 78, 1291-1297.

Ghanem Romdhane, N., Bonazzi, C., Kechaou, N., \& Mihoubi, N. B. (2015). Effect of air-drying temperature on kinetics of quality attributes of lemon (Citrus limon cv. lunari) peels. Drying Technology, 33(13), 1581-1589.

Ghanem, N., Mihoubi, D., Kechao, N. \& Mihoubi, N. B. (2012). Microwave dehydration of three citrus peel cultivars: Effect on water and oil retention capacities, color, shrinkage and total phenols content. Industrial Crops and Products, 40, 167-177.

Gonçalves, E. M., Pinheiro, J., Abreu, M., Brandão, T. R. S. \& Silva, C. L. (2010). Carrot (Daucus carota L.) peroxidase inactivation, phenolic content and physical changes kinetics due to blanching. Journal of Food Engineering, 97(4), 574-581.

Gonzalez-Fesler, M., Salvatori, D., Gomez, P., \& Alzamora, S. M. (2008). Convective air drying of apples as affected by blanching and calcium impregnation. J. of Food Engin., 87(3), 323-332.

Gölükcü, M. (2015). The effects of drying methods. packaging atmosphere and storage time on dried pomegranate aril quality. Tarım Bilimleri Dergisi, 21(2), 207-219.

Hawlader, M. N. A., Perera, C. O. \& Tian, M.. (2006). Properties of modified atmosphere heat pump dried foods. Journal of Food Engineering, 74(3), 392-401.

İzli, G., İzli, N., Taşkın, O., \& Yııldı, G. (2018). Convective drying of kumquat slices: comparison of different drying temperatures on drying kınetics, colour, total phenolic content and antioxidant capacity. Latin American Applied Research, 48(1), 37-42.

Jiang, N., Liu, C., Li, D., Zhang, Z., Liu, C., Wang, D., \& Zhang, M.. (2017). Evaluation of freeze drying combined with microwave vacuum drying for functional okra snacks: Antioxidant properties, sensory quality, and energy consumption. LWT-Food Sci. and Tech., 82, 216-226.

Joshi, A. P. K., Rupasinghe, H. P. V., \& Khanizadeh, S. (2011). Impact of drying processes on bioactive phenolics, vitamin C and antioxidant capacity of red-fleshed apple slices. Journal of Food Processing and Preservation, 35(4), 453-457.

Koyasako, A., \& Bernhard, R. A. (1983). Volatile constituents of the essential oil of kumquat. Journal of Food Science, 48(6), 1807-1812.

Krokida, M. \& Maroulis, Z. (2000). Quality changes during drying of food materials. Drying Technology in Agriculture and Food Sciences, 4(2), 61-68.

Lou, S. N., Lai, Y. C., Huang, J. D., Ho, C. T., Ferng, L. H. A., \& Chang., Y. C. (2015). Drying effect on flavonoid composition and antioxidant activity of immature kumquat. Food Chemistry, 171, 356-363.

Marques, L.G., Silveira, A.M., \& Freire, J.T. (2006). Freze- Drying characteristics of tropical fruits. Drying Technology,24, 457-463.

Methakhup, S., Chiewchan, N., \& Devahastin, S. (2005). Effects of drying methods and conditions on drying kinetics and quality of Indian gooseberry flake. $L W T, 38,579-587$.

Michalska, A., Wojdyło, A., Honke, J., Ciska, E., \& Andlauer, W. (2018). Drying-induced physicochemical changes in cranberry products. Food Chemistry, 240, 448-455.

Michalska, A., Wojdyło, A., Lech, K., Łysiak, G. P., \& Figiel, A. (2016). Physicochemical properties of whole fruit plum powders obtained using different drying technologies. Food Chemistry, 207, 223-232. 
Özcan-Sinir, G., Özkan-Karabacak, A., Tamer, C. E., \& Çopur, O. U. (2018). The effect of hot air, vacuum and microwave drying on drying characteristics, rehydration capacity, color, total phenolic content and antioxidant capacity of Kumquat (Citrus japonica). Food Science and Technology (Campinas), 39(2), 475-484.

Pala, M., \& Saygi, Y. B. (1983). Su Aktivitesi ve Gıda İşletmedeki Önemi. Gıda Dergisi, 8(1), 33-39.

Pathare, P. B., Opara, U. L. \& Al-Said, F. A. J. (2013). Colour measurement and analysis in fresh and processed foods: a review. Food and Bioprocess Technology, 6(1), 36-60.

Rahman, M. S. (2007). Food Preservation: Overview. In: Rahman.M.S. (Ed.). (pp. 3-18) Handbook of Food Preservation Boca Raton, FL, USA, CRC Press.

Rodríguez, Ó., Gomes, W., Rodrigues, S., \& Fernandes, F. A. (2017). Effect of acoustically assisted treatments on vitamins, antioxidant activity, organic acids and drying kinetics of pineapple. Ultrasonics Sonochemistry, 35, 92-102.

Saç1lık, K. (2007). Effect of drying methods on thin-layer drying characteristics of hull-less seed pumpkin (Cucurbita pepo L.). Journal of Food Engineering, 79, 23-30.

Sagar, V. R., \& Kumar, P. S. (2010). Recent advances in drying and dehydration of fruits and vegetables: a review. Journal of Food Science and Technology, 47(1), 15-26.

Santos, P. H. S., \& Silva, M. A. (2008). Retention of vitamin C in drying processes of fruits and vegetables-A review. Drying Technology, 26(12), 1421-1437.

Schirra, M., Palma, A., Aquino, S.D., Angioni, A., Minello, E.V., Melis, M., \& Cabras., P. (2008). Influence of postharvest hot water treatment on nutritional and functional properties of kumquat (Fortunella japonica Lour. Swingle Cv. Ovale) Fruit. Journal of Agricultural and Food Chemistry, 56, 455-460.

Sdiri, S., A. Bermejo, Aleza, P., Navarro, P., \& Salvador, A. (2012). Phenolic composition, organic acids, sugars, vitamin $\mathrm{C}$ and antioxidant activity in the juice of two new triploid late-season mandarins. Food Research International, 49(1), 462-468.

Toker, O. S., Doğan, M., Ersöz, N. B., \& Yilmaz, M. T. (2013). Optimization of the content of 5hydroxymethylfurfural (HMF) formed in some molasses types: HPLC-DAD analysis to determine effect of different storage time and temperature levels. Industrial Crops and Products, 50, 137-144.

Tontul, I., \& Topuz, A. (2017). Effects of different drying methods on the physicochemical properties of pomegranate leather (pestil). LWT-Food Science and Technology, 80, 294-303.

Topuz, A., Feng, H. \& Kushad, M. (2009). The effect of drying method and storage on color characteristics of paprika. LWT-Food Science and Technology, 42(10), 1667-1673.

Touati, N., Tarazona-Díaz, M. P., Aguayo, E., \& Louaileche, H. (2014). Effect of storage time and temperature on the physicochemical and sensory characteristics of commercial apricot jam. Food chemistry, 145, 23-27.

Uddin, M. S., Hawlader, M. N. A., Ding, L., \& Mujumdar, A. S. (2002). Degradation of ascorbic acid in dried guava during storage. Journal of Food Engineering, 51(1), 21-26.

Udomkun, P., Nagle, M., Argyropoulos, D., Mahayothee, B., Latif, S., \& Müller, J. (2016). Compositional and functional dynamics of dried papaya as affected by storage time and packaging material. Food chemistry, 196, 712-719.

Us, F. (2006). Meyve ve Sebzelerin Kurutularak Muhafazası. In: Acar.J, V.Gökmen ve F. Us. (Eds.). Meyve veSebze Işsleme Teknolojisi Cilt 2. (s.241-297). Ankara, Türkiye: H.Ü. Yayınları.

Us, F. (2007). Su ve Buz. In: Saldamlı.İ. (Ed.). Gida Kimyası. (s.9-42). Türkiye: H.Ü. Yayın. Ankara.

Veberic, R., Jurhar, J., Mikulic-Petkovsek, M., Stampar, F., \& Schmitzer, V. (2010). Comparative study of primary and secondary metabolites in 11 cultivars of persimmon fruit (Diospyros kaki L.). Food Chemistry, 119(2), 477-483.

Vega-Gálvez, A., Di Scala, K., Rodríguez, K., Lemus-Mondaca, R., Miranda, M., López, J., \& PerezWon, M. (2009). Effect of air-drying temperature on physico-chemical properties, antioxidant capacity, colour and total phenolic content of red pepper (Capsicum annuum, L. var. Hungarian). Food Chemistry, 117(4), 647-653.

Wang, J., Yang, X. H., Mujumdar, A. S., Wang, D. J., Zhao, H., Fang, X. M., \& Xiao, H. W. (2017). Effects of various blanching methods on weight loss, enzymes inactivation, phytochemical contents, antioxidant capacity, ultrastructure and drying kinetics of red bell pepper (Capsicum annuum L.). LWT-Food Science and Technology, 77, 337-347. 
Wang, J., Yang, X. H., Mujumdar, A. S., Fang, X. M., Zhang, Q., Zheng, Z. A., \& Xiao, H. W. (2018). Effects of high-humidity hot air impingement blanching (HHAIB) pretreatment on the change of antioxidant capacity, the degradation kinetics of red pigment, ascorbic acid in dehydrated red peppers during storage. Food Chemistry, 259, 65-72.

Wang, Y.W., Zeng, W.C., Xu, P.Y., Lan, Y.J., Zhu, R.X., Zhong, K. Y., Huang, N., \& Gao, H. (2012). Chemical composition and antimicrobial activity of the essential oil of Kumquat (Fortunella crassifolia Swingle) Peel. International Journal of Molecular Sciences, 13, 3382-3393.

Yen, Y. H., Shih, C. H., \& Chang, C. H. (2008). Effect of adding ascorbic acid and glucose on the antioxidative properties during storage of dried carrot. Food Chemistry, 107(1), 265-272. 